\title{
IMPACT OF PSYCHOLOGICAL HEALTH ON ACADEMIC PERFORMANCE OF MEDICAL STUDENTS. WHERE DO WE STAND?
}

Hamna Khan ${ }^{\mathrm{a}}$, Ain-ul-Mominab ${ }^{\mathrm{b}}$, Muhammad Zeeshan Sarwar ${ }^{\mathrm{c}}$

${ }^{a}$ Post Graduate Resident, North Surgical Ward Mayo Hospital, Lahore.

${ }^{\mathrm{b}}$ Assistant Professor, Department of Community Medicine, King Edward Medical University, Lahore.

${ }^{\mathrm{c} A s s i s t a n t}$ Professor, Department of Surgery, East Surgical Ward Mayo Hospital, Lahore.

\begin{abstract}
:
BACKGROUND \& OBJECTIVE: The objective of our study is to evaluate the prevalence of anxiety, stress and depression in undergraduate MBBS students to correlate it with self-efficacy, life satisfaction and to evaluate its effect on academic performance. We have also considered the relation between academic year and last year score.

METHODOLOGY: A total of 800 self-administered questionnaires were filled by $1^{\text {st }}$ year to final year undergraduate students using non-probability, purposive sampling. The 10-minute questionnaire comprised of four sections: (1) demographics (2) Depression, Stress and Anxiety Scale (DASS ) 21 scoring system (3) Satisfaction with Life Scale (4) General Self-Efficacy Scale. The demographic questions included participants' age, gender, and year of study, residence and last year professional examination score percentage. A percentage below $50 \%$ was named as low achievers. A percentage from $50 \%$ to $70 \%$ was considered as moderate achievers and above $70 \%$ as high achievers.

RESULTS: In this sample of 505 students 180 (35.6\%) were male undergraduates consisting of $18.6 \%$ from $1^{\text {st }}$ year, $26.5 \%$ from $2^{\text {nd }}$ year and $20.8 \%, 18 \%$ and $16 \%$ from $3^{\text {rd }}$ year, $4^{\text {th }}$ year and final year respectively. The depression, anxiety and stress rate were $69.5 \%, 78.6 \%$ and $63.4 \%$ respectively. Generally, depression, anxiety and stress were found more in females as compared to males. Anxiety was more common as compared to stress and depression. Students of $4^{\text {th }}$ year were experiencing least psychological stress.

CONCLUSION: Moderate level of depression, stress and anxiety is necessary for good grades but excess of these psychological problems leads to emotional exhaustion and has a negative effect on learning and academic score. These psychological problems also lower the general self-efficacy of a student and are associated with low satisfaction with life.
\end{abstract}

KEYWORDS: DASS-21, Satisfaction with life scale, General self-efficacy, Undergraduate medical students, King Edward Medical University.

How to cite this:

doi: https://doi.org/10.37723/jumdc.v11i3.425

Khan $H$, Momina AU, Sarwar MZ. IMPACT OF PSYCHOLOGICAL HEALTH ON ACADEMIC PERFORMANCE OF MEDICAL STUDENTS. WHERE DO WE STAND?.jumdc. 2020;11(3):31-38.

doi: https://doi.org/10.37723/jumdc.v11i3.425

This is an Open Access article distributed under the terms of the Creative Commons Attribution License (http://creativecommons.org/licenses/by/4.0), which permits unrestricted use, distribution, and reproduction in any medium, provided the original work is properly cited. 


\section{INTRODUCTION:}

Medicine is generally considered as one of the most difficult and exhausting fields of education as its academic and professional requirements are quite demanding. Extended curricula, on and off detailed examinations and fear to fail are few causes of continuous and persistent stress, depression and anxiety among medical students ${ }^{[1]}$. Most common and important root factors of stress in Pakistani medical students' life are examinations, hectic, tough and frequent long duration study classes ${ }^{[2]}$. Various studies witnessed a high prevalence of psychological disorders among students of the medical profession. As per universal review published in 2006, medical students of United States of America and Canada suffer from a greater incidence of psychological disorders, self-destructive thoughts and suicidal ideation as compared to the general population ${ }^{[3]}$. Many other studies have shown the prevalence of psychological disorders in medical students of different ethnic groups. Incidence of stress was found to be $20.9 \%$ in a medical institute of Nepal, $63.8 \%$ in a medical school of Saudi Arabia And About $90 \%$ in a medical institute situated in Pakistan ${ }^{[4-6]}$.

Psychological distress among students studying in medical school has detrimental results and thus brings about poor academic performance, sleep disturbances, alcohol misuse, disturbed relationships and skepticism ${ }^{[7,8]}$.

The psychological health of these students has also been demonstrated as self-efficacy and satisfaction with life ${ }^{[9]}$. It has been shown that students' self-efficacy trusts their capabilities and thus has a strong impact on their academic performance. Previous studies have claimed a strong association between self-efficacy and academic performance of students ${ }^{[10]}$.

Multiple studies have shown the association between stress and academic achievement among Pakistani MBBS students. However, few studies showed the bright side of psychological health, in the form of life satisfaction and selfefficacy among Pakistani MBBS students. So, the study determines the psychological health (including its both bright and negative sides) and its association with academic outcome for MBBS students of KEMU, Lahore, Pakistan.

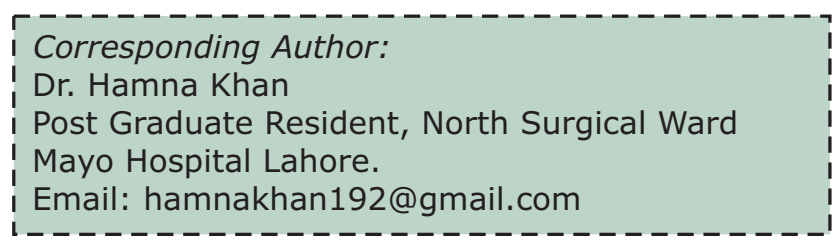

\section{METHODOLOGY:}

King Edward Medical University, Lahore, Pakistan (KEMU) offers a 5-year-long Bachelors program of Medicine and Surgery (MBBS) which is divided into 2 preclinical years and 3 clinical years. University use a combination of conventional and new teaching procedures, which consists of teacher-centered instructional methods, long duration lectures, lessons, seminars and practical teaching. Students are on and off evaluated with written exams, vivas and practical's throughout the year, and at the end of each year a final examination is conducted by the University. A passing grade of $50 \%$ is compulsory for promotion to next academic year.

This cross-sectional study was held at KEMU, Lahore. The study has been approved by the institutional review board of King Edward Medical University, Lahore. Students from all academic years of the MBBS degree program, enrolled with University during the study period were included in this study. Students who were on psychological treatment or medications were not included in this study. Study was conducted from February, 2018 to April, 2018. This study period was quite suitable and accurate ahead of examinations. A total of 800 self-administered question papers were given out to undergraduate students of $1^{\text {st }}$ year to final year using non-probability, purposive sampling. Two verbal reminders were given over a period of seven days. A total of 505 students returned filled questionnaires. We got the signed written informed consent from all participants of this research program. They were guided about the objective of this study and were assured anonymity.

The 10 minute questionnaire consisted of four sections: (1) Demographics (2) Depression, Stress and Anxiety Scale (DASS) 21 scoring system (3) Satisfaction with Life Scale (4) General Self-Efficacy Scale. The demographic questions included participants' age, gender, and year of study, residence and last year 
professional examination score percentage. A percentage below $50 \%$ was named as low achievers. A percentage from $50 \%$ to $70 \%$ was considered as moderate achievers and above $70 \%$ as high achievers.

The DASS 21 Scale was utilized to evaluate anxiety, depression and stress, and it showed us the negative side of psychological health. It comprised of 21 questions, each question answered on answer scale from 0-3. Anxiety, depression and stress had seven questions each. Question numbered 3, 5, 10, 13, 17, 16 and 21 were designed for depression. The question numbered 2, 4, 7, 9, 15, 20, 19 were designed for anxiety. Whereas question numbered $1,6,8,11,14,12$ and 18 were evaluating stress. In DASS- 21 scoring system, normal scores were 0-4 depression score, 0-3 anxiety score and 0-7 stress score. Mild grade was given a score of 5-6 for depression, 4-5 for anxiety and 8-9 for stress. A score 7-10 for depression, 6-7 for anxiety while 10-12 for stress was labeled as moderate grade. Severe category included 11-13 depression score, 8-9 anxiety score, and 13-16 stress score. Any score above these values were categorized as extremely severe categories.

The bright side of psychological health was evaluated by General Self-Efficacy (GSE) scale and Satisfaction with Life Scale (SWLS). GSE comprised 10 questions, each question marked from 1-4, providing a collective score of 10 to 40. A score of 10 indicates no self-efficacy. A score of 11-20 represents low self-efficacy while score of 21-30 was considered as moderate self-efficacy. Finally a score of $31-40$ showed high self-efficacy. SWLS consisted of five questions, each question scores from 1-7, resulting in a total score 5 to 35 . Extremely satisfied score was labeled for a score of 31-35. A score of 26-30 and 21-25 was considered as satisfied and slightly satisfied respectively while score 20 marked as neutral. A score of 15-19 showed a slightly dissatisfied person. A score of 10-14 was classified as dissatisfied and a score of $<9$ was considered as extremely dissatisfied. All data was entered in SPSS 22. All scores were categorized and cross tabulated to identify the impact of positive (GSE \& SWLS) and negative aspects (DASS 21) of psychological well-being on academic performance using independent sample $\mathrm{t}$ test and chi-square test. P-value $\leq$ 0.05 was considered significant.

\section{RESULTS:}

Total 505 students correctly filled the form. Out of those 505 students 180 (35.6\%) were male undergraduates and $325(64.4 \%)$ were female undergraduates. About $18.6 \%$ students were from $1^{\text {st }}$ year, $26.5 \%$ were from $2^{\text {nd }}$ year and $20.8 \%, 18 \%$ and $16 \%$ were from $3^{\text {rd }}$ year, $4^{\text {th }}$ year and final year respectively.

The depression, anxiety and stress rates were $69.5 \%, 78.6 \%$ and $63.4 \%$ respectively. Mean stress in female undergraduates was significantly $(p=0.03)$ higher $(2.46 \pm 1.31$ vs $2.21 \pm 1.22$ ) as compared to male students. The mean depression level in male undergraduates $(2.57 \pm 1.45)$ was not significantly $(p=0.070)$ different from female undergraduates $(2.81 \pm 1.44)$. similarly, there was no significant $(p=0.535)$ difference in mean anxiety between male (3.26 \pm 1.49$)$ and female (3.34 \pm 1.50$)$ undergraduates. It showed only DASS stress score in female undergraduates was significantly higher in female undergraduates as compared to male undergraduates.

Association of DASS score with gender and academic scores showed a significant relationship of stress with academic scores $(p=$ 0.015 ) Table I. According to academic years, depression scores were not significantly associated with academic years $(p=0.28)$ Figure-I. Though stress $(p=0.01)$ and anxiety score $(p=0.05)$ had significant association with academic scores respectively. (Figure-II, III). The mean value of Satisfaction with Life Scale was $(22.96 \pm 6.45)$ and the mean of General Self-Efficacy (GSE) was (27.40 \pm 5.62). Significant association was found between stress and GSE only $(p=0.05)$ (Table-II). 
Table-I: Association of DASS score with gender and academic score.

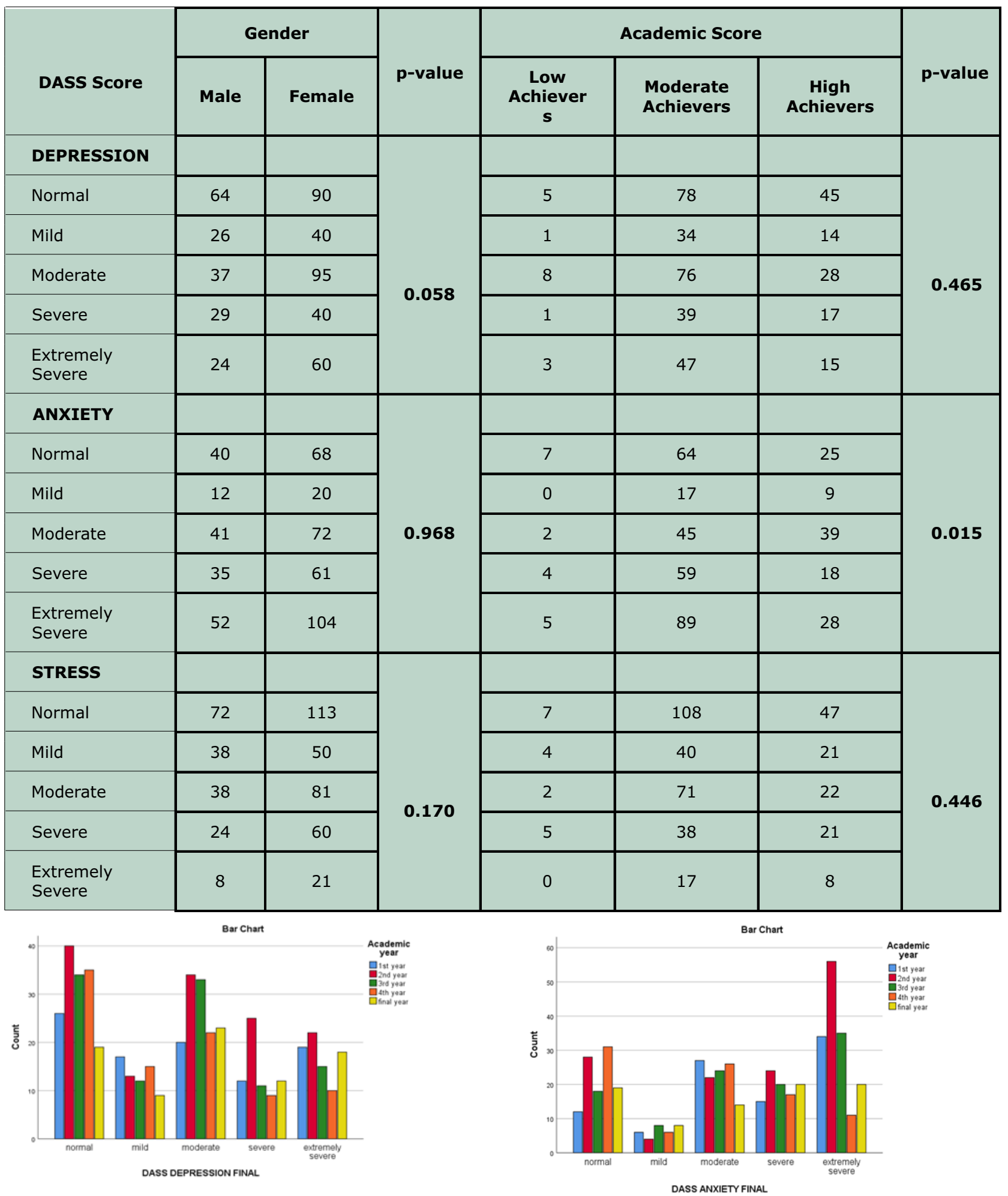

Figure-I: Association of Depression score with academic year.

$x^{2}=18.78, d f=16, p=0.28$
Figure-II: Association of anxiety score with the academic year.

$x^{2}=29.81, d f=16, p=0.01$ 


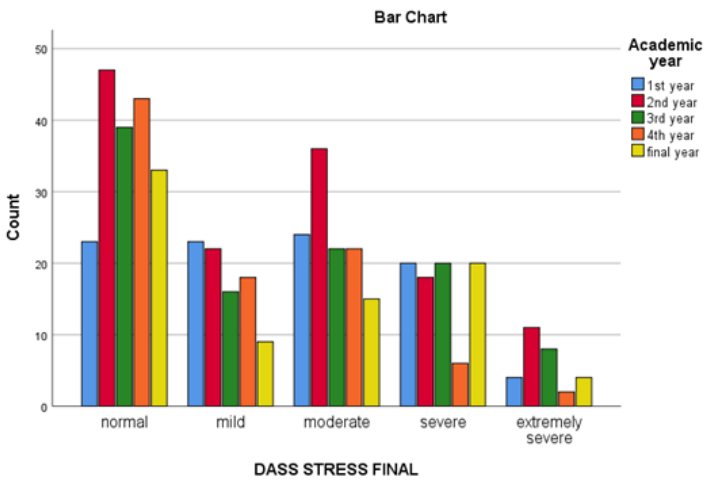

Figure-III: Association of Stress score with academic year. $x^{2}=41.31, d f=16, p=0.05$

Table-II: Association of DASS score with General Self Efficacy (GSE) and Satisfaction With Life Scale (SWLS). (In SWLS, 1 is Extremely Dissatisfied, 2 is Dissatisfied, 3 is Slightly Dissatisfied, 4 is Neutral, 5 is Slightly Satisfied, 6 is Satisfied, 7 is Extremely Satisfied).

\begin{tabular}{|c|c|c|c|c|c|c|c|c|c|c|c|c|c|}
\hline \multirow[b]{2}{*}{ DASS SCORE } & \multicolumn{4}{|c|}{ General Self Efficacy } & \multirow{2}{*}{$\begin{array}{c}\text { p- } \\
\text { value }\end{array}$} & \multicolumn{7}{|c|}{ Satisfaction With Life Scale } & \multirow{2}{*}{$\begin{array}{c}\text { p- } \\
\text { value }\end{array}$} \\
\hline & NO & LOW & Moderate & High & & 1 & 2 & 3 & 4 & 5 & 6 & 7 & \\
\hline \multicolumn{13}{|l|}{ DEPRESSION } & \multirow{6}{*}{0.12} \\
\hline Normal & 0 & 12 & 89 & 53 & \multirow{5}{*}{0.39} & 15 & 13 & 24 & 7 & 41 & 41 & 23 & \\
\hline Mild & 0 & 10 & 37 & 19 & & 1 & 7 & 8 & 1 & 25 & 18 & 6 & \\
\hline Moderate & 0 & 15 & 84 & 32 & & 6 & 15 & 18 & 7 & 35 & 42 & 7 & \\
\hline Severe & 0 & 9 & 44 & 16 & & 1 & 4 & 9 & 9 & 19 & 22 & 5 & \\
\hline $\begin{array}{l}\text { Extremely } \\
\text { Severe }\end{array}$ & 1 & 12 & 47 & 24 & & 0 & 7 & 19 & 5 & 19 & 22 & 12 & \\
\hline \multicolumn{13}{|l|}{ ANXIETY } & \multirow{6}{*}{0.75} \\
\hline Normal & 0 & 6 & 70 & 32 & \multirow{5}{*}{0.31} & 3 & 9 & 17 & 3 & 26 & 35 & 15 & \\
\hline Mild & 0 & 4 & 19 & 09 & & 0 & 4 & 4 & 2 & 9 & 9 & 4 & \\
\hline Moderate & 0 & 13 & 63 & 37 & & 4 & 11 & 22 & 2 & 32 & 33 & 9 & \\
\hline Severe & 1 & 10 & 62 & 22 & & 2 & 10 & 14 & 8 & 30 & 24 & 6 & \\
\hline $\begin{array}{l}\text { Extremely } \\
\text { Severe }\end{array}$ & 0 & 25 & 87 & 44 & & 4 & 12 & 21 & 14 & 42 & 44 & 19 & \\
\hline \multicolumn{13}{|l|}{ STRESS } & \multirow{6}{*}{0.61} \\
\hline Normal & 0 & 13 & 119 & 53 & \multirow{5}{*}{0.05} & 5 & 16 & 31 & 8 & 49 & 54 & 21 & \\
\hline Mild & 1 & 13 & 51 & 23 & & 3 & 4 & 10 & 3 & 24 & 35 & 9 & \\
\hline Moderate & 0 & 21 & 57 & 40 & & 3 & 11 & 16 & 9 & 37 & 30 & 12 & \\
\hline Severe & 0 & 8 & 58 & 18 & & 2 & 11 & 18 & 8 & 20 & 18 & 7 & \\
\hline $\begin{array}{l}\text { Extremely } \\
\text { Severe }\end{array}$ & 0 & 3 & 16 & 10 & & 0 & 4 & 3 & 1 & 9 & 8 & 4 & \\
\hline
\end{tabular}




\section{DISCUSSION:}

Academic pressure due to tough nature of medical practice and course work cause stress, anxiety and depression in medical students. Other potential cause of stress, anxiety and depression might be the involvement of human suffering, death, sexuality and fear. In medical colleges stress in students may lead to poor mental and physical health, reduction in self esteem of the student, negative impact on cognitive function and learning of the students. Damage to the psychological health has been reported in multiple researches. This depression and anxiety among medical students has not been only reported in developing countries, but also in developed countries. Psychological distress is a subjective experience. In other words, psychological discomfort may interfere with different subjective experiences and activities ${ }^{[11]}$.

The subjective comfort has been conceived as a combination of two major elements: the emotional element and the cognitive element ${ }^{[12]}$. Researchers have proposed that general self-efficacy (GSE) can be considerably thrown into organizational theory, research, and practice ${ }^{[13]}$. General self-efficacy is the trust in one's ability to make out with a wide range of hard and difficult requirements ${ }^{[14]}$.

In this present study it was noted that the depression, anxiety and stress rates were $69.5 \%, 78.6 \%$ and $63.4 \%$ respectively, with stress level showing a significant association with female gender. These results were in agreement with other studies like in a carried out in Saudi Arabia, the prevalence of stress among medical students was recorded $71.9 \%$, with female students having predominantly higher rate of stress than males ( $77 \%$ vs $64 \%$, p $<0.01)^{[15]}$. Another study also showed parallel results of anxiety and SWLS which were sensitive to gender and year of the study.

Literature has also shown the association of self-efficacy with gender. In a study it was observed that Self-efficacy was higher among female students as compared to male students. Life satisfaction score was comparatively higher among 2nd-year students as compared to other academic years. Depression was found to be the only variable that was associated with the academic scores. Female medical students were found to be suffering from higher psychological distress than males ${ }^{[16]}$. The results of our study are also parallel to these results and we found that mean value of Satisfaction with Life Scale was significantly higher in females with mean value of general self-efficacy $(27.40 \pm 5.62)$ as compared to mean value of $(22.96 \pm 6.45)$ in male students.

The stress, anxiety and depression levels have shown association with class of the medical student. In our study it was found out that moderate, severe and extremely severe depression was most common among 2 nd year students. It was also found out that moderate anxiety was most commonly associated with 1st year medical students and severe and extremely severe anxiety with 2 nd year medical students. In terms of stress, severe stress was more common among 1st year, 3rd year and final year students ${ }^{[17,18]}$.

The results are similar in developed countries like a study from Sweden, used first year, third year and final year medical students to assess the stress, anxiety and depression levels ${ }^{[19]}$. In that study more females were found to be suffering from stress, anxiety and depression as compared to males. First year medical students were facing severe pressure from tough studies in contrast to other classes. Female undergraduates were found to be taking more stress than males ${ }^{[20]}$. Other local data also showed the same trend like a study from wah medical college showed Higher anxiety and depression scores with a significant association with gender $(p=0.007)$ and year of study $(p=0.001)$. Both anxiety and depression symptoms were quite frequent in 2 nd year medical students with $43 \%$ students with depression and $61.6 \%$ with anxiety ${ }^{[21]}$.

The main limitation of this study is that sample has been taken from students of all five-year students from a single medical institute. Only one scale for calculation of anxiety, stress and depression was used. The sample was not diverse enough to assess differences between private and public sector medical institute. 


\section{CONCLUSION:}

It is concluded from the results of this study that psychological morbidity is very common in medical students. The female undergraduate students, $1^{\text {st }}$ and $2^{\text {nd }}$ year medical students were most commonly found to be stressed, anxious and depressed. Special attention should be given on psychological well being of the medical students for prevent distress among them. Further studies on larger level are recommended to explore causes, consequences, and solutions for this problem rather than simply describing it.

\section{ACKNOWLEDGMENT: None}

CONFLICT OF INTEREST: All authors disclose no conflict of interest.

\section{GRANT SUPPORT\& FINANCIAL DISCLOSURES: None.}

\section{REFERENCES:}

1. Shah M, Hasan S, Malik S, Sreeramareddy CT. Perceived stress, sources and severity of stress among medical undergraduates in a Pakistani medical school. BMC Medical Education. 2010;10(1):2. DOI:10.1186/ 1472-6920-10-2

2. Naseem S, Orooj F, Ghazanfar H, Ghazanfar A. Quality of life of Pakistani medical students studying in a private institution. Journal of Pakistan Medical Association. 2016;5:579-583.

3. Frajerman A, Morvan Y, Krebs MO, Gorwood $P$, Chaumette B. Burnout in medical students before residency: a systematic review and meta-analysis. European Psychiatry. 2019;55:36-42. DOI: 10.1016/j.eurpsy.2018.08.006

4. Imran N, Tariq KF, Pervez MI, Jawaid M, Haider II. Medical students' stress, psychological morbidity, and coping strategies: a cross-sectional study from Pakistan. Academic Psychiatry.
2016;40(1):92-96. DOI $10.1007 /$ s40596015-0413-y

5. Abdulghani HM, AlKanhal AA, Mahmoud ES, Ponnamperuma GG, Alfaris EA. Stress and its effects on medical students: a crosssectional study at a college of medicine in Saudi Arabia. Journal of health, population, and nutrition. 2011;29(5):516-522. DOI: $10.3329 /$ jhpn.v29i5.8906 PMID: 22106758

6. Fares J, Al Tabosh H, Saadeddin Z, El Mouhayyar C, Aridi H. Stress, burnout and coping strategies in preclinical medical students. North American journal of Medical Sciences. 2016;8(2):75-81. DOI: 10.4103/1947-2714.177299 PMID: 27042604

7. Mayer FB, Santos IS, Silveira PS, Lopes MH, de Souza AR, Campos EP, et al. Factors associated to depression and anxiety in medical students: a multicenter study. BMC Medical Education. 2016;16(1):282. DOI.10.1186/s12909-016-0791-1

8. Becker SP, Jarrett MA, Luebbe AM, Garner $A A$, Burns $G L$, Kofler MJ. Sleep in a large, multi-university sample of college students: sleep problem prevalence, sex differences, and mental health correlates. Sleep Health. 2018;4(2):174-181. DOI: 10.1016/j.sleh.2018.01.001 PMID: 29555131

9. Kumar V, Talwar R, Raut DK. Psychological distress, general self-efficacy and psychosocial adjustments among first year medical college students in New Delhi, India. South East Asia Journal of Public Health. 2013;3(2):35-40. DOI: 10.3329/ seajph.v3i2.20038

10. Khan AS, Cansever Z, Avsar UZ, Acemoglu $H$. Perceived self-efficacy and academic performance of medical students at Ataturk University, Turkey. Journal of the College of Physicians Surgeon Pakistan. 2013;23(7):495-498. 
11. Selamu LG, Singhe MS. Mental health distress and academic performance of medical students: a review. Journal of Psychology \& Clinical Psychiatry. 2018;9(6):675-678.

12. Samaha M, Hawi NS. Relationships among smartphone addiction, stress, academic performance, and satisfaction with life. Computers in Human Behavior. 2016;57:321-325. DOI:10.1016/j.chb. 2015.12.045

13. Chen G, Gully SM, Eden D. Validation of a new general self-efficacy scale. Organizational research methods. $2001 ; 4(1): 62-83$. DOI: $10.1177 /$ 109442810141004

14. Kerr SP, Kerr WR, Xu T. Personality Traits of Entrepreneurs: A Review of Recent Literature. Foundations and Trends in Entrepreneurship. 2018;14(3):279-356. Available from: https://www.nber.org/ papers/w24097.pdf

15. Sani M, Mahfouz MS, Bani I, Alsomily AH, Alagi D, Alsomily NY, et al. Prevalence of stress among medical students in Jizan University, Kingdom of Saudi Arabia. Gulf Medical Journal. 2012;1(1):19-25.

16. Aboalshamat $K$, Hou XY, Strodl E. Psychological well-being status among medical and dental students in Makkah, Saudi Arabia: A cross-sectional study. Medical teacher. 2015;37(sup1):S75-81. DOI:0.3109/0142159X.2015.1006612

17. Iqbal S, Gupta S, Venkatarao E. Stress, anxiety \& depression among medical undergraduate students \& their sociodemographic correlates. The Indian journal of medical research. 2015;141(3): 354-357. PMID: 25963497

18. Basnet B, Jaiswal M, Adhikari B, Shyangwa PM. Depression among undergraduate medical students. Kathmandu University Medical journal. 2012;10(3):56-59.

19. Wahed WY, Hassan SK. Prevalence and associated factors of stress, anxiety and depression among medical Fayoum University students. Alexandria Journal of medicine. 2017;53(1):77-84. DOI:10. 1016/j.ajme.2016.01.005

20. Dahlin M, Joneborg N, Runeson B. Stress and depression among medical students: A cross sectional study. Medical education. 2005;39(6):594-604. DOI: $10.1111 / \mathrm{j}$. 1365-2929.2005.02176.x

21. Alvi T, Assad F, Ramzan M, Khan FA. Depression, anxiety and their associated factors among medical students. Journal of College of Physicians and Surgeons Pakistan. 2010;20(2):122-126.

\section{Authors' Contribution:}

Hamna Khan: Acquisition of data, drafting of the manuscript.

Ain-ul-Momina: Analysis and interpretation of data.

Muhammad Zeeshan Sarwar: Final editing \& proof reading

Submitted for publication: 19.05.2020

Accepted for publication: 22.08 .2020

After Revision 